\title{
O papel dos organismos internacionais na evolução dos estudos populacionais no Brasil: notas preliminares
}

\author{
George Martine*
}

\begin{abstract}
O artigo analisa a influência das agências internacionais na evolução dos estudos populacionais no Brasil. O notável crescimento da área de demografia no país foi impulsionado, em parte, pela preocupação internacional com o crescimento populacional e pelos recursos colocados à nossa disposição. Os organismos internacionais que queriam influenciar a questão populacional no Brasil optaram por um de dois caminhos. A Usaid e o FNUAP (até a Conferência do Cairo) aliaram-se principalmente às entidades que promoviam o planejamento familiar e, por esse caminho, a redução da fecundidade. A Fundação Ford, a Organização Pan-Americana de Saúde, o Population Council e a Fundação Rockefeller adotaram uma estratégia menos direta, que acabou sendo mais proveitosa para o Brasil: estimularam a formação de uma massa crítica capaz de assumir a iniciativa do pensamento político na área populacional. Direta ou indiretamente, isto acabou beneficiando os pesquisadores e as diversas instituições de ensino e pesquisa agora existentes no país. O doador internacional com maior influência ao longo do tempo tem sido a Fundação Ford. A Fundação MacArthur imprimiu uma nova abordagem ao financiamento de estudos populacionais, antevendo a visão do Cairo. Hoje, o FNUAP, na sua versão pósCairo, é praticamente o único doador que continua apoiando esse campo do conhecimento, o que exigirá dos pesquisadores maior criatividade para continuar expandindo a influência dos estudos populacionais no futuro.
\end{abstract}

Palavras-chave: Agências internacionais de financiamento de estudos. Avanços da demografia. Políticas demográficas. Brasil.

\section{Introdução}

A oportunidade de participar da reunião bianual da Abep em 2004, depois de alguns anos de ausência, foi para mim motivo de muita alegria. Entre outras coisas, pude presenciar o enorme crescimento da nossa Associação, assim como sua maturidade, apesar de ela ainda não ter completado 30 anos de vida. A profusão de caras novas na reunião, a diversidade de temas, bem como o perfil profissional mais diversificado dos participantes, deram-me uma sensação muito viva não somente de ebulição, mas também de evolução na nossa Abep.

Por outro lado, junto com a impressão de estar vendo tanta gente nova, foi muito marcante para mim a ausência de algumas figuras tradicionais, fundadoras da nossa Associação e presença obrigatória tanto nas

* Consultor independente e presidente da Associação Brasileira de Estudos Populacionais (Abep), gestão 2005/2006. 
assembléias como nos debates intermináveis na borda da piscina. Deu-me a sensação de que estava ocorrendo uma rápida substituição e troca da guarda. Esta, por sua vez, provocou-me uma reação que deve ser pavloviana em todos nós que estamos ficando mais velhinhos. Pensei: "Puxa, alguém teria de contar para eles a nossa história. Garanto que a grande maioria dos que estão aqui hoje não tem a mínima idéia do que foram as nossas origens como associação ou como campo de estudos. Nós mesmos estamos arriscados a esquecer nossa trajetória e nossas belas conquistas!". Foi nesse exato momento que chegou a Bete Bilac, então editora desta revista, com uma proposta que me pareceu sensacional: montar um número especial da Rebep que buscaria, justamente, fazer um retrospecto de todo o processo de constituição do campo da demografia no Brasil. Feliz coincidência e brilhante idéia!

Segundo a divisão de trabalho proposta pela Rebep, caberia a mim fazer uma retrospectiva da participação dos organismos internacionais na evolução dos estudos populacionais no Brasil. Topei a parada (ainda se usa essa expressão dos meus bons tempos?), enfim, aceitei o desafio! Não porque tenho informações privilegiadas a respeito, e muito menos porque tenho uma memória prodigiosa - na verdade, o meu disco duro já apresenta tantas falhas que parece queijo suíço -, mas sim porque acho imprescindível alguém tentar cobrir esse aspecto importante da nossa história. Embora não tenha o pedigree necessário para ser historiador (fora a idade avançada!), eu me disponho a dar um primeiro passo nesse sentido. Tenho a esperança de que este esforço servirá para que outras pessoas possam aperfeiçoar, corrigir, enfim, melhorar esse pequeno relato preliminar. Como o leitor já terá observado, para escrever este ensaio abandonei o estilo formal clássico de trabalhos profissionais. Trata-se de uma visão pessoal, baseada parcialmente em relatos pessoais, e não vejo razão para dissimular essas vivências subjetivas com pseudo-academicismos. Várias pessoas contribuíram com depoimentos orais ou escritos a este pequeno ensaio histórico. ${ }^{1}$

\section{O neomalthusianismo e a explosão dos estudos demográficos}

Embora os estudos de população e a demografia sejam relativamente antigos, eles eram, até pouco tempo, propriedade de um grupo relativamente restrito de especialistas, geralmente atuários e estatísticos. Na década de 40 , começou a primar o interesse acadêmico pela "teoria da transição demográfica". Esta teoria enfatizava a importância de mudanças estruturais como precondição para mudanças no comportamento reprodutivo e nos níveis de fecundidade. Na década de 50 , a percepção de que uma explosão demográfica global estava por ocorrer, devido aos níveis de crescimento dos países pobres, gerou um súbito interesse público pelos temas populacionais. É notável como, nesse momento, a visão da transição demográfica lenta e gradual foi rapidamente substituída por uma atitude positivista dirigida a controlar o crescimento demográfico iminente que estava sendo projetado pelos especialistas.

De fato, nessa época, os estudos de Notestein, Davis, Hauser, da Escola de Princeton e muitos outros apontavam para um provável aumento acelerado do crescimento populacional e analisavam os perigos que este representava (Szreter, 1993; Hodgson, 1991). Esses autores deram legitimidade a esforços bilaterais e multinacionais para controlar a fecundidade

\footnotetext{
${ }_{1}^{1}$ Para preparar este ensaio, procurei, inter alia, as seguintes pessoas: Elza Berquó, José Alberto M. de Carvalho, Valdecir Lopes, Carmen Barroso, Hélio Moura, Tom Merrick, Axel Mundigo, Charles Wood, Mary Kritz, Oscar Harkavy, Leo Morris, Joe Potter, Guaraci Adeodato Alves de Souza, Neide Patarra, Sérgio Nadalin, José Miguel Guzman e Guiomar Bay. A grande maioria dessas pessoas dispôs generosamente de seu tempo e alguns até mandaram textos escritos, citados na bibliografia ao final deste trabalho. Agradeço, de forma particular, os apoios e as informações gentilmente fornecidos por Elza Berquó e as sugestões de José Alberto M. de Carvalho.
} 
dos países pobres. Lograram convencer a opinião pública de que não convinha esperar as lentas e complexas transformações econômicas e culturais que, segundo a teoria da transição demográfica, teriam que preceder uma redução significativa da fecundidade. Campanhas massivas de planejamento familiar, anteriormente menosprezadas como um "quick fix" ineficaz, passaram então a ser amplamente preconizadas. Imediatamente, começaram a surgir recursos, fundações, institutos e organismos internacionais dedicados, explicitamente, cada qual à sua maneira, a combater a ameaça do rápido crescimento demográfico.

A formulação clássica daquilo que viria a ser chamado de neomalthusianismo encontra-se no trabalho de Coale e Hoover, do final da década de 50 . Em seguida, vários outros argumentos da mesma natureza foram sendo elaborados, condenando a alta fecundidade. Embora tenham aparecido, imediatamente, sólidos argumentos econômicos que relativizavam as ameaças preconizadas pelo neomalthusianismo inclusive o famoso livro das Nações Unidas, Determinantes e conseqüências das tendências populacionais (United Nations, 1953) -, esta segunda linha de argumentação nunca conseguiu neutralizar a simplicidade atraente da tese controlista. Não obstante, é interessante constatar que, depois de suas primeiras incursões no neomalthusianismo, a maioria dos demógrafos e cientistas sociais passou logo a adotar, na década de 60 , posturas mais cautelosas (Wilmoth e Ball, 1992). Apesar disso, o caudal dos controlistas foi sendo engrossado por gente poderosa como John D. Rockefeller. Como os cientistas sociais de sua própria Fundação relutavam contra a idéia de envolver-se em atividades "pragmáticas" na área populacional, foi criado, por iniciativa de Rockefeller, o
Population Council. ${ }^{2}$ Rockefeller foi acompanhado, nessa preocupação, por várias outras entidades, inclusive a Fundação Ford. Entretanto, o evento mais importante na cruzada contra o crescimento demográfico foi a estréia da United States Agency for International Development (Usaid) no campo populacional, no ano de 1965. Depois de muita relutância, a Usaid estava entrando definitivamente em ação, com uma estratégia simplificada de planejamento familiar que deixava de considerar todas as sutilezas das discussões ocorridas nas duas décadas anteriores (Demeny, 1994, p. 7). Essa entrada em cena da Usaid deu uma nova agressividade a todos os esforços controlistas. Mais tarde, em 1969, foi criado o Fundo de População das Nações Unidas (FNUAP), que em 1971 passou a ser o organismo das Nações Unidas responsável por "programas de população".

No plano intelectual, não parece ser coincidência o fato de que foram os biólogos e os ecologistas que tomaram a bandeira neomalthusiana a partir de meados da década de 60. Desde esse momento, eles têm mantido aceso o debate a respeito dos impactos do crescimento demográfico. Seguiram incursionando sem temor nem remorso em temas sociopopulacionais complicados, alguns dos quais os próprios cientistas sociais evitavam tocar, ou tratavam com muito cuidado. Inclusive é divertido ver que, no prólogo de seu penúltimo livro, Paul Ehrlich comenta, com muito orgulho, que ele tinha conseguido uma transição fácil do estudo das populações de mariposas (sua especialidade) ao estudo das populações humanas! (Ehrlich et al., 1995, prefácio).

$\mathrm{O}$ fato de que a visão neomalthusiana era muito simples e atraente, tanto para o público como para os políticos dos países desenvolvidos, acabou gerando uma cruzada global a favor da redução da

\footnotetext{
2 "In 1952, the world was awakening to the rapid growth in population that was occurring around the globe. Impressed by the complexities of population issues, convinced of their fundamental significance for human well-being, and undeterred by the sensitivity then associated with birth control, John D. Rockefeller 3rd convened a group of scientists to discuss the implications of the dramatic demographic change. They met in Williamsburg, Virginia, under the auspices of the National Academy of Sciences, and after two and a half days, agreed on the need for a new institution (the Population Council) that could provide solid science to guide governments and individuals in addressing population questions." Population Briefs, Population Council, v. 9, n. 2, June 2003.
} 
fecundidade. A maioria dos países subdesenvolvidos do mundo inteiro foi instada a formular "políticas de população", entendidas, basicamente, como "políticas de planejamento familiar que levariam à redução da fecundidade". Para ajudar a convencer o público e os políticos da necessidade de tais políticas, e para implementá-las eficazmente, foram direcionados recursos vultosos para a formação de recursos humanos em demografia e temas conexos, assim como para a geração de dados e a análise dos mesmos. Também foram inventados e apresentados, ad nauseam, vários modelinhos destinados a demonstrar ao mundo inteiro a desgraça que ocorreria se os países pobres não conseguissem reduzir rapidamente seu crescimento.

$O$ que tem tudo isso a ver com o desenvolvimento dos estudos populacionais no Brasil? Muito! Tudo! De alguma maneira, a maioria de nós que trabalhamos na área de população somos produto e beneficiários da preocupação (quase paranóia) nascida em torno à explosão demográfica. De fato, essa preocupação neomalthusiana está na origem da rápida expansão dos estudos de população no mundo inteiro, a partir da década de 60. Apesar de a atenção da área populacional estar centrada, naquela época, nas formas de reduzir a fecundidade, criouse, paralelamente, um espaço privilegiado de estudos, pesquisas, conferências e publicações em torno do tema populacional lato sensu. Isso estimulou uma expansão muito rápida da demografia. $\mathrm{O}$ apoio que os estudos de população recebeu, em comparação com as outras áreas sociais, é bastante privilegiado, particularmente no período 1965-95. Ao longo das últimas décadas foram disponibilizados muito mais recursos fáceis para trabalhar questões de população do que para analisar outros temas sociais igualmente importantes como nutrição, delinqüência, marginalidade, analfabetismo etc.

No Brasil, especificamente, é notável o crescimento da área de demografia. Em 1960, o país ainda tinha poucos profissionais com formação na área de população. Quinze anos depois, o crescimento desse grupo havia sido tão rápido que possibilitou a formação da Abep, com a participação de amplos setores da academia, associação que hoje reúne centenas de pessoas interessadas nos temas relacionados à população. Não creio que haja outra disciplina, pelo menos nas ciências sociais, que possa competir com esse crescimento. Queiramos ou não, este avanço foi impulsionado, em parte, pela preocupação internacional com o crescimento populacional e pelos recursos colocados à nossa disposição.

Isto, obviamente, não quer dizer que todos nós que estudamos demografia, tanto na década de 60 como posteriormente, sejamos neomalthusianos. Muito pelo contrário! Quando o neomalthusianismo chegou com força no Brasil, a partir de meados da década de 60 , ele já enfrentou uma predisposição crescente da intelectualidade a rejeitar toda forma de "imperialismo" - inclusive essa tentativa, vinda do exterior, de influenciar os padrões de reprodução da população brasileira. Nesse particular, é interessante observar que a questão populacional era um dos poucos temas no qual direita e esquerda se encontravam. A maioria dos militares e seus amigos conservadores - ciosos da soberania nacional, desconfiados das intenções controlistas alheias e ainda confiantes na força do número de braços -, conjuntamente com os antiimperialistas de esquerda, opunham-se a qualquer iniciativa estrangeira que pudesse influenciar o ritmo de crescimento demográfico do país.

Esse sentimento de que tudo o que cheirava demografia e estudos populacionais teria laços com o imperialismo teve diversas conseqüências no início dos estudos populacionais, tanto brasileiros como latino-americanos. Por um lado, o patruIhamento ideológico, inclusive dos colegas, estava sempre a um passo dos pioneiros e dos doadores na demografia brasileira. ${ }^{3}$ Essa envoltura ideológica contribuiu, inter

\footnotetext{
${ }^{3}$ A Fundação Interamericana, "agência independente do governo norte-americano" que financiava estudos e projetos no Brasil, chegou a ser expulsa do país em 1977, presumivelmente por seu ardor controlista na época.
} 
alia, para retardar o reconhecimento de que milhões de mulheres brasileiras buscavam desesperadamente acesso a serviços de saúde reprodutiva desde a década de 60.

"O significado real do planejamento familiar para os indivíduos e famílias de baixa renda - que carregavam o ônus da responsabilidade pelas rápidas taxas de reprodução não foi objeto de discussão explícita na época, em vista da reação extremamente negativa às pressões internacionais e da predominância de atitudes de laissez-faire com respeito ao assunto." (Martine e Faria, 1986, p. 7).

Por outro lado, os organismos internacionais que queriam influenciar a questão populacional no Brasil tiveram de optar por um de dois caminhos. A Usaid e o FNUAP (até a época do Cairo) terminaram se aliando quase exclusivamente às entidades que se dedicavam a promover o planejamento familiar e, por esse caminho, a redução da fecundidade. Outros, como a Fundação Ford, a Organização Pan-Americana de Saúde (Opas), o Population Council e a Fundação Rockefeller, adotaram uma estratégia menos direta, que acabou sendo mais proveitosa para o Brasil. Resolveram estimular a formação de uma massa crítica de brasileiras e brasileiros capazes de assumir a iniciativa do pensamento político na área populacional. Para tanto, promoveram a capacitação de recursos humanos e a atividade científica, deixando que o melhor conhecimento da dinâmica demográfica e não a postura neomalthusiana - levasse à devida consideração dos fatores demográficos no planejamento nacional. A seguir, passo a relatar alguns lances e histórias de iniciativas que, como pequenos rios, se juntaram para formar o caudal dos estudos populacionais no Brasil.

\section{Os principais atores internacionais nos estudos populacionais no Brasil}

Sem fazer uma pesquisa mais aprofundada é difícil atrever-se a listar ou classificar as contribuições das diversas entidades que apoiaram, de uma forma ou de outra, o desenvolvimento dos estudos populacionais no Brasil. Vou fazer, pois, um relato das informações que consegui colher, com a esperança de que isso sirva para que outras pessoas, com melhores dados, possam ir corrigindo e ampliando o que segue. Primeiro, traço rapidamente a evolução do ensino da demografia no Brasil e, depois, analiso o papel das entidades e

\section{Quem diria? A influência estrangeira na demografia brasileira também tem raízes no fascismo europeu!}

Pois é, um dos primeiros e maiores demógrafos no Brasil foi um judeu italiano, Giorgio Mortara, o qual já tinha mostrado toda sua clarividência e sua capacidade de fazer projeções ao fugir do fascismo no final da década de 30. "Mortara chegou ao Brasil, aos 54 anos de idade, em 19 de janeiro de 1939. Como tantos outros intelectuais, tivera de deixar sua terra natal para escapar da desenfreada perseguição racial com que as feras do fascismo e nazismo mancharam de vergonha a velha Europa [...] Contam os fatos que sua decisão de escolha do nosso país para imigrar, entre outros tantos motivos de foro íntimo, que só lhe pertenciam, deve ter sido determinada pelo convite formulado por autoridades brasileiras para que viesse colaborar na preparação do recenseamento geral de 1940." (Berquó e Bercovich, 1985, p. 21-22).

Logo em seguida, Mortara criou escola. Nas palavras de Valdecir Lopes, um dos pioneiros do IBGE: "Oilustre professor Giorgio Mortara, nascido na Itália e vindo para o Brasil em razão da II Grande Guerra, encontrou a melhor acolhida no IBGE. Ali o professor Mortara, como era conhecido, encontrou campo fértil para criar seu Laboratório de Estatística, para onde atraiu jovens ibgeanos com certa formação matemática, e os encaminhou no trato com a demografia, usando a simplicidade que lhe era peculiar para salvar a falta de dados primários existentes no país e utilizar, muitas vezes, métodos alternativos ou não convencionais em seus estudos." (Lopes, 2004, p. 1).

Embora seja difícil dizer exatamente quantos trabalhos Mortara legou ao Brasil, a lista de suas obras chega à casa de 973 publicações, versando sobre os mais diferentes temas. "Mesmo considerando que muitas delas versam sobre o mesmo tema, apresentado em revistas diferentes, ainda assim, trata-se de uma volumosa bibliografia, que testemunha sua grande e contínua capacidade de trabalho. [...] vale a pena salientar que a despeito do relativo vazio de informações [...] a grande capacidade técnica e a experiência acumulada por Mortara no trato dos fenômenos demográficos [...] aliada à extrema sensibilidade, conferiu-Ihe a arte de intuir ou conjeturar [...] Por outro lado, a carência encontrada permitiu a Mortara desenvolver métodos e técnicas originais que desde logo passaram a beneficiar outros países sofrendo da mesma falta de estatísticas do estado civil ou censos incompletos e pouco fidedignos." (Berquó e Bercovich, 1985, p. 22 e 24). 
doadores internacionais na promoção dos estudos demográficos no país.

\section{O ensino da demografia e o apoio internacional}

\section{Celade}

A primeira instituição latino-americana a oferecer cursos de demografia de forma regular foi o Centro Latino-Americano de Demografia (Celade). Estabelecido por um convênio entre as Nações Unidas e o Governo do Chile, o Celade iniciou suas atividades em agosto de 1957, sob a competente direção de Carmen Miró, reunindo um reduzido grupo de demógrafos com experiência internacional. Seus objetivos eram então:

1. organizar cursos sobre técnicas de análise demográfica para estudantes de países latino-americanos e fomentar o estabelecimento de cursos semelhantes em seus países;

2. promover estudos sobre problemas demográficos, com base nas fontes de informação existentes ou em estudos de campo;

3. atuar como órgão de consulta sobre problemas demográficos dos governos de países latino-americanos ou de seus organismos. (página Web, Celade)

A importância do Celade é ressaltada no seguinte depoimento de Valdecir Lopes:

Cabe ao Centro Latino-Americano de Demografia um papel de destaque, por suas atividades multiplicadoras em prol da demografia e dos estudos de população, não só no Brasil, mas em toda a América Latina. [...] Além dos cursos realizados em suas sedes de Santiago do Chile e de San José da Costa Rica, o Centro promoveu cursos intensivos em associação com entidades de ensino superior, como a Pontifícia Universidade Católica do Rio de Janeiro, entre outras, de onde saíram muitos dos atuais demógrafos que atuam no país.

$[\ldots]$

Não menos importante foi a influência do Celade em pesquisas inovadoras, realizadas nas décadas de 60 e 70, em busca de solução para os problemas das projeções demográficas em países com estatísticas incompletas, como era o caso do Brasil e de muitos países da região. Assim é que, em
1961, realizou-se, em caráter experimental, a "Pesquisa da Guanabara", mediante o procedimento de visitas sucessivas à população estudada, com a assistência técnica do Centro, em colaboração com o IBGE. Não deixaram, também, de representar uma contribuição as projeções de população elaboradas pelo Celade e os vários estudos comparados, abrangendo países da região. Entre estes, destacam-se as análises realizadas a partir das amostras dos censos demográficos da década de 1970, reunidas no Banco de Dados do Centro. Pode-se afirmar, portanto, que a atual demografia brasileira, que ocupa posição de relevo no continente, muito deve à contribuição recebida de ilustres demógrafos nacionais e de outros, vinculados a organismos internacionais, como o Centro LatinoAmericano de Demografia, dirigido, na época, por Carmen A. Miró, uma das mais brilhantes figuras da América Latina nessa área de atividade. (Lopes, 2004, p. 2)

$A$ isto vale agregar que o Celade realizou cursos, estudos e pesquisas de campo no Brasil. As pesquisas PecfalUrbana e Pecfal-Rural geraram dados importantes para o estudo da dinâmica brasileira, além de introduzir inovações metodológicas. Além do ensino a vários jovens demógrafos brasileiros, o Centro também promoveu cursos de iniciação aos estudos demográficos no Brasil. Pela relação fornecida pelo próprio Celade, 70 brasileiros teriam feito cursos promovidos pela instituição seja no Brasil, seja no Chile. Pelos nomes citados, observa-se que muitos deles são abepianos que iniciaram seus estudos demográficos via Celade.

\section{Cedip}

Diante da necessidade de dotar o país de centros universitários de pesquisa e ensino voltados para o estudo das questões populacionais, Elza Berquó, então responsável pelo Departamento de Estatística Aplicada da Faculdade de Saúde Pública da Universidade de São Paulo, contatou a Organização Pan-Americana de Saúde (Opas) a fim de buscar apoio para viabilizar tal iniciativa. Em 1965, a Opas propiciou a vinda a São Paulo da consultora dra. Irene Taueber, da Universidade de Princeton, então uma das mais destacadas demógrafas em âmbito mundial e com particular 
interesse na área da saúde. De um trabalho conjunto entre a dra. Taueber e Elza Berquó materializou-se a idéia de criar o Centro de Estudos da Dinâmica Populacional (Cedip), anexo ao Departamento de Estatística Aplicada da Faculdade de Saúde Pública da USP.

A Opas aprovou recursos para financiar a criação e o funcionamento do Cedip por um período de cinco anos, após os quais o compromisso seria assumido pela Faculdade de Saúde Pública. Além disso, financiou também os estudos de cinco profissionais, oriundos de várias disciplinas. Assim, Paul Singer, economista, foi fazer um doutorado na Universidade de Princeton; Neide Patarra, socióloga, foi para a Universidade de Chicago; João Yunes, médico, foi para a Universidade de Michigan; Jair Lício Ferreira Santos, estatístico, para Chicago (e posteriormente, Berkeley), e Cândido Procópio Ferreira de Camargo, sociólogo de notório saber, recebeu financiamento para visitas a diversos centros de população no mundo mais desenvolvido. Elza Berquó foi a primeira diretora do Cedip, que passou a funcionar em 1967, oferecendo um curso em demografia e iniciando algumas pesquisas.

Entretanto, o Cedip foi seriamente afetado pelo Al-5, que afastou Elza Berquó e Paul Singer da USP. Com a saída de Berquó, Cândido Procópio Ferreira de Camargo assumiu a direção do Centro, mas a iniciativa foi perdendo ímpeto. Além do mais, a USP não honrou o compromisso de financiamento do Cedip depois dos primeiros cinco anos de funcionamento. As atividades de pesquisa e ensino em demografia na USP passaram, então, a ser exercidas, durante alguns anos, sob a liderança de Neide Patarra, no Programa de Estudos em Demografia e Urbanização (Prodeur), dentro da Faculdade de Arquitetura e Urbanismo. Por outro lado, uma doação da Fundação Ford permitiu a criação do Centro Brasileiro de Análise e Planejamento (Cebrap) em 1969, no qual se abrigou parte do núcleo original do Cedip. A partir dessa migração, o Cebrap passou a ser um dos principais esteios dos estudos populacionais no Brasil.

O Cedip e o Cebrap foram, portanto, as primeiras entidades não-governamentais a desenvolver estudos demográficos de modo sistemático no Brasil. A incursão de jovens pesquisadores, já reconhecidos na academia e politicamente progressistas, nesse tema fez muito para legitimá-lo perante a comunidade intelectual e política. Nas palavras de Martine e Faria (1986, p. 11):

Os estigmas de intervencionismo estrangeiro e de imperialismo que pesavam, de forma difusa, sobre os estudos populacionais foram se desfazendo gradativamente, à medida que intelectuais de prestígio, perseguidos abertamente pelo regime, passaram a se dedicar aos estudos populacionais e contribuíram de maneira estratégica para a concepção de abordagens originais sobre a questão populacional na América Latina. Essas contribuições independentes ajudaram a legitimar e difundir ainda mais o interesse pela área.

\section{Cedeplar}

A trajetória do Centro de Desenvolvimento e Planejamento Regional (Cedeplar), da Universidade Federal de Minas Gerais, também deve muito ao apoio internacional recebido, conforme descrito na página Web da instituição:

Desde sua criação, o Cedeplar vem mantendo estreitos laços de relacionamento com instituições nacionais e internacionais, sejam acadêmicas ou de outra natureza, que lhe garantiram considerável ajuda para sua criação e consolidação institucional. Assim é que, em seus primeiros anos de existência, instituições como BNDES, Ipea, Fundação Ford, USP, Institute of Social Studies de Haia tiveram importância decisiva na formação dos [seus] quadros acadêmico e administrativo, seja por meio de apoio técnico-científico, seja por meio de financiamentos de suas atividades.

\section{$[\ldots]$}

Posteriormente, outras instituições, como órgãos federais e estaduais da administração pública (os diversos ministérios, a FIBGE etc.), Fundações Rockefeller, Hewlett, as Nações Unidas, através do FNUAP, desempenharam papel importante no esforço de ampliação e consolidação das atividades do Centro. <http://www.cedeplar. ufmg.br/sobreocedeplar.html\#HISTORICO>

As primeiras aulas de demografia na UFMG foram dadas no Programa de 
Mestrado de Economia Regional, em 1969. Conforme o depoimento de Elza Berquó:

[a Ford] contribuiu para que fossem abertos cursos com o fim de aglutinar economistas interessados nessa especialização. Paralelamente, com suas bolsas de doutoramento, tornou possível o treinamento, em renomados centros do exterior, de um grupo de economistas-demógrafos. De volta ao país, iniciaram eles, em 1974, um importante programa de Demografia com a introdução de uma área de concentração nessa disciplina no mestrado em economia. (Berquó, 1992, p. 170)

Um dos jovens economistas beneficiados com uma bolsa da Ford foi José Alberto Magno de Carvalho, que partiu para fazer seu doutorado na London School of Economics em 1970, de lá regressando no final de 1973 com seu Ph.D. na mão. Posteriormente, José Alberto viria a ser o primeiro presidente eleito da Abep e, anos mais tarde, presidente da União Internacional para o Estudo Científico da População (IUSSP).

Entre 1970 e 1979, a Fundação Ford apoiou a vinda ao Cedeplar de professores visitantes para dar maior consistência e caráter internacional ao ensino da demografia. O Cedeplar inaugurou seu programa de mestrado em demografia em 1976 e seu doutorado em 1985. Para tanto, recebeu contribuições importantes tanto da Fundação Rockefeller como da Fundação Hewlett.

\section{Nepo}

De acordo com a sua página $W e b$, o Núcleo de Estudos de População (Nepo)

é uma unidade de pesquisa interdisciplinar e multidisciplinar na área de Demografia e Estudos de População da Universidade Estadual de Campinas (Unicamp). Criado pela Portaria GR 28, de 25 de maio de 1982, consolidou-se com a Deliberação do ConseIho Universitário (Consu) de 27 de novembro de 1991. O Nepo está vinculado à Coordenadoria de Centros e Núcleos (Cocen) e à Coordenadoria Geral da Unicamp. <http://www.unicamp.br/nepo>

Embora os Núcleos da Unicamp não sejam unidades docentes, o Nepo participa ativamente do Programa de Pós-Graduação em Demografia do Instituto de Filosofia e Ciências Humanas.

A trajetória do Nepo difere daquela do Cedeplar, no sentido de que a instituição não recebeu aportes específicos estrangeiros para a implementação e realização do seu programa básico. Nesse particular, foram mais importantes os auxílios financeiros recebidos da Finep e do CNPq. Entretanto, na realização dos seus trabalhos de pesquisa e de cursos especializados, o Nepo recebeu apoios significativos da Fundação Ford, do FNUAP e de outros, conforme relacionado no Quadro $1 \mathrm{em}$ anexo. Vale mencionar, especialmente, o apoio da Ford para o Programa de Saúde Reprodutiva e Sexualidade (1990-2004) e para o Programa Interinstitucional de Treinamento em Metodologia de Pesquisa em Gênero, Sexualidade e Saúde Reprodutiva (1994-2004), assim como o apoio do FNUAP para o Programa Interinstitucional de Avaliação e Acompanhamento das Migrações Internacionais no Brasil.

\section{Outras instituições de ensino}

A Universidade Federal do Paraná, em Curitiba, tem oferecido cursos de mestrado e doutoramento em demografia histórica. De acordo com um dos seus professores mais ilustres, Sérgio Nadalin, estes cursos não tiveram apoio internacional. Em seu depoimento, por e-mail, Nadalin informa:

Gostaria de lhe dar algo substantivo, mas em verdade tudo o que nosso programa de pós-graduação conseguiu realizar foi muito mais em função da "presença" de Altiva e Cecília, naqueles tempos, nos nossos organismos financiadores - pelo que eu me lembro, Capes e CNPq. Foi dessa maneira que trouxemos vários franceses, inclusive Louis Henry e Jacques Dupâquier, para Curitiba.

Em compensação, o Centro de Recursos Humanos $(\mathrm{CRH})$ da Universidade Federal da Bahia, apesar de não ter recebido apoio sistemático de nenhuma entidade internacional específica, conseguiu, desde o início da década de 70, um grande número de apoios para eventos e pesquisas. A lista dessas contribuições, gentilmente preparada pelo $\mathrm{CRH}$, por intermédio de 
Guaraci Adeodato Alves de Souza, inclui 27 financiamentos para pesquisas e 10 bolsas oriundas de organismos internacionais. O Quadro 2 (em anexo) revela a grande variedade de fontes de financiamento obtidas pelo $\mathrm{CRH}$, desde 1970, para trabalhos e estudos na área de população.

Depois dessa rápida incursão no mundo do ensino, passo agora a examinar a contribuição de alguns organismos e financiadores internacionais.

\section{Organismos e financiadores internacionais dos estudos populacionais}

\section{Fundação Ford}

A julgar pelas informações disponíveis, o doador internacional com mais influência nos estudos populacionais no Brasil, ao longo do tempo, tem sido a Fundação Ford. Por esse motivo, e pelo fato de que um artigo da professora Elza Berquó já nos traz uma valiosa fonte de informações históricas a respeito da atuação da Ford no Brasil, este vai ser o maior capítulo desta minha novela.

Os primeiros tempos de atuação da Ford no campo populacional no Brasil não foram registrados, mas fica claro que essa fundação já tinha uma estratégia bem articulada desde meados da década de 60 . No âmbito dos países industrializados, a partir do momento em que McGeorge Bundy assumiu a presidência da Ford, em 1966, a Fundação seguiu uma orientação claramente neomalthusiana. Esta ideologia institucional somente viria a ser reformulada na década de 80. Entretanto, todos os escritórios regionais e nacionais da Ford localizados nos países em desenvolvimento tinham plena autonomia na utilização dos recursos - sabendo, claro, que o tema tinha prioridade na agenda do presidente da Fundação (Harkavy, 1995, p. 38-39). Esta política descentralizada permitiu ao escritório da Ford no Brasil fazer uma leitura mais correta da sensibilidade política da questão populacional no país e, conseqüentemente, propor medidas mais apropriadas a esse contexto.

\author{
Conforme Berquó (1992, p. 167),
}

na esfera de preparação de recursos humanos no âmbito acadêmico dos estudos populacionais, a Fundação Ford iniciou suas atividades em nosso país na segunda metade da década de 1960, principalmente por meio de bolsas de estudos no exterior.

A intenção clara da Ford (seguida posteriormente por outros como o Population Council, a Fundação Rockefeller e, mais recentemente, a Fundação Hewlett) era fortalecer a capacidade nacional para analisar as questões demográficas brasileiras. O primeiro oficial de programa da Ford para assuntos populacionais no país de que se tem conhecimento foi José Hernandez, um jovem demógrafo portoriquenho simpático e de bem com a vida. Em 1969, o escritório brasileiro da Ford recebeu uma missão de consultores e demógrafos americanos, liderados por Ansley Coale, que, aparentemente, teria sido fundamental na definição da estratégia da Fundação para o país. Logo depois, Robert McLaughlin chegou ao Brasil para assumir a função de oficial de programa para assuntos de população e planejamento familiar.

Paralelamente, conforme já mencionado, a Ford teve um papel decisivo na estruturação do Centro Brasileiro de Análise e Planejamento (Cebrap), organismo que acolheu os professores da USP demitidos pelo Al-5 em 1969.

Com recursos institucionais da Ford e, específicos para pesquisa, do International Development Research Center (IDRC), do Canadá, o Cebrap conduziu, em meados da década de 1970, a Pesquisa Nacional sobre Reprodução Humana. Essa pesquisa, dado seu escopo, trouxe consideráveis subsídios para a elucidação de questões básicas da problemática populacional, mediados pelo papel das instituições. (Berquó, 1992, p. 70)

Após o regresso dos bolsistas da Ford ao Brasil, em 1973-74, a Fundação lançou mão de uma outra iniciativa destinada a fortalecer o ensino da demografia no país.

Com a dupla finalidade de oferecer oportunidade e condições de trabalho de investigação a seus bolsistas, quando do regresso ao país, e atrair para a pesquisa 
em população professores e investigadores com treinamento em campos afins, a Fundação Ford criou, em 1972, um Programa de Bolsas de Pesquisa. [...] o Programa concedeu em apenas seis anos um total de 68 bolsas para investigação. (Berquó, 1992, p. 169)

A Ford também teve um papel importante no desenvolvimento do ensino acadêmico da demografia dentro do Brasil. Até o final dos anos 60, as únicas entidades acadêmicas na região latino-americana com cursos de pós-graduação em demografia eram o Celade e El Colégio de México. Em 1970, a Fundação Ford apoiou a vinda de professores visitantes para dar cursos de demografia no Mestrado de Economia do Cedeplar. Em 1972, o Population Council enviou um consultor, Axel Mundigo, para sondar as perspectivas institucionais para 0 fortalecimento do ensino da demografia no Brasil. Após visitar várias instituições acadêmicas brasileiras, juntamente com McLaughlin (da Ford), Mundigo concluiu que, naquele momento, o Cedeplar era o programa em melhores condições para promover o avanço do estudo acadêmico da demografia no país (Mundigo, 2004).

Para apoiar os novos demógrafos que retornavam ao Cedeplar, a Ford financiou a vinda de um demógrafo norte-americano, Tom Merrick, contratado como professor adjunto no Cedeplar. Enquanto permaneceu nesse posto, entre 1970 e 1974, Merrick foi um ator fundamental, junto com McLaughlin, no posicionamento da Ford e, conseqüentemente, na promoção dos estudos populacionais no Brasil. Seu sucessor, Charles Wood, continuou exercendo o mesmo papel de apoio, no Cedeplar e na Ford, de 1974 a 1979.

Em 1976, Axel Mundigo voltou ao Brasil para substituir Robert McLaughlin como oficial de programa da Ford. Juntamente com Merrick e Wood, Mundigo teve um papel destacado na formação da própria Abep. A intenção da Ford, naquele momento, era transferir a coordenação de estudos demográficos para uma entidade brasileira de caráter associativo (Berquó, 1992, p. 171). Observando o rápido cresci- mento dos estudos demográficos no país, eles se articularam com algumas figuras mais representativas da demografia brasileira nascente - João Lyra Madeira, Elza Berquó, José Alberto M. de Carvalho, Manoel Costa, Helio Moura, inter alia - para propor uma primeira reunião nacional sobre o progresso dos estudos populacionais brasileiros. Esta foi realizada em 1976. Carmen Miró, Ansley Coale e Isaac Kerztenestsky estavam entre os ilustres convidados a esse evento e, segundo suas próprias palavras, estiveram muito impressionados com a capacidade de pesquisa que estava sendo mostrada naquela reunião.

Os resultados da reunião foram publicados na forma de alguns livros, dos quais tive a honra de editar um chamado, singelamente, Migrações internas (Martine, 1977). No prefácio desse livro leio:

O Simpósio sobre o Progresso da Pesquisa Demográfica no Brasil foi realizado no Rio de Janeiro, em junho de 1976, sob os auspícios da Fundação Ford, com o objetivo de estabelecer uma maior comunicação entre os cientistas interessados em demografia. Pesquisadores de todo o país e do exterior reuniram-se para apresentar resultados e conclusões de seus trabalhos e debater a atual e futura situação dos estudos populacionais no Brasil.

Axel Mundigo, referindo-se a esse evento, recorda que muitas das pesquisas apresentadas no simpósio haviam sido financiadas pela Ford.

Entretanto, o resultado mais importante do simpósio foi, sem dúvida, a criação da Abep. Mundigo (2004, p. 2) relata:

Em conversas com o professor Lyra Madeira, o reconhecido decano dos estudos populacionais no Brasil dessa época, e com Elza Berquó, surgiu a idéia de usar a reunião do Sheraton para apresentar à Assembléia a possibilidade de criar uma associação de população no Brasil. $\mathrm{Na}$ medida em que essa idéia foi circulando na rede de pessoas interessadas, a reação foi muito positiva.

Um pequeno comitê, apoiado na sua logística pela Ford, foi criado para redigir os estatutos da nova associação, cuja situação foi institucionalizada legalmente 
em fevereiro de 1978. O primeiro Encontro da Abep, para o qual o apoio da Ford foi novamente fundamental, foi realizado em Campos do Jordão (SP), durante o mês de outubro de 1978. Posteriormente, a Ford continuou financiando várias reuniões técnicas menores da Abep.

A partir de 1979, cortes nos recursos orçamentários da Ford para o seu escritório regional fizeram com que o Brasil deixasse de ter um oficial de programa na área de população. A Abep assumiu então a administração do Concurso de Bolsas de Pesquisa.

Nos dez anos que se seguiram, concursos anuais foram realizados, totalizando aproximadamente uma centena de projetos de pesquisa [...] cobrindo os mais variados temas no âmbito dos estudos populacionais [...] Com a retirada do suporte financeiro da Fundação Ford, em 1989, o programa é interrompido (Berquó, 1992, p. 171 e 173).

A própria Revista Brasileira de Estudos Populacionais (Rebep), fundada em 1982 (e cujo primeiro número apareceu em 1984), contou com o apoio decisivo da Ford para cobrir os custos de sua edição.

De 1985 a 1990 a Abep contou com expressivas e contínuas dotações para a execução de seu amplo programa editorial, que além da revista inclui também um boletim informativo trimestral, anais de encontros bianuais e publicações avulsas de seminários temáticos. Infelizmente, o apoio foi interrompido a partir de 1990 . (Berquó, 1992, p. 174).

Finalmente, a Ford beneficiou a Abep com um endowment de valor equivalente ao dobro da contraparte brasileira. Este permitiu à Associação gerar uma renda pequena, mas estável, para financiar parte de suas atividades. Com mais esta iniciativa, a Ford pretendia dar à Abep uma base financeira suficiente para poder enfrentar seus compromissos técnicoadministrativos.
Fundação Rockefeller, Population Council, Fundação Hewlett e IDRC

Conforme observado anteriormente, o Population Council foi fundado em 1952 como o braço mais operacional da Fundação Rockefeller na área de população. ${ }^{4}$ Entretanto, o Council recebeu recursos de muitas outras fontes, inclusive US\$ 88 milhões da Fundação Ford, entre 1957 e 1993 (Harkavy, 1995, p. 13). Vale a pena contar algo aqui sobre a história brasileira da Rockefeller e do Population Council, inclusive porque suas políticas no Brasil foram muito parecidas com aquelas aplicadas pela Ford. De fato, Harkavy relata que, no âmbito de suas respectivas sedes, as três instituições compartiam estratégias explicitamente e colaboravam freqüentemente no desenho e execução de projetos (idem, p. 44-45).

De acordo com as informações obtidas, a primeira colaboração de um organismo internacional aos estudos populacionais brasileiros teria sido feita pela Fundação Rockefeller, em 1959. O beneficiário desse apoio foi a Fundação Joaquim Nabuco, de Recife. De acordo com Mary Kritz, oficial de programa da Rockefeller nas décadas de 70 e 80 e atual secretária-geral da IUSSP, tratava-se de um recurso relativamente pequeno, que se destinava a avaliar as conseqüências do crescimento demográfico no Nordeste. Em 1973, a Rockefeller também apoiou um estudo da Universidade Federal da Bahia sobre emprego e subemprego no Nordeste. Também naquela época, financiou um estudo realizado pela Universidade Federal do Ceará. A Abep recebeu uma só contribuição da Rockefeller, no valor de US\$ 3,5 mil, em 1977. O Cebrap foi o beneficiário de um apoio de US\$ 88,5 mil para realizar uma pesquisa, coordenada por Paul Singer, sobre os determinantes demográficos da participação na força de trabalho.

Entretanto, a maior contribuição da Rockefeller aos estudos populacionais no

\footnotetext{
4 " [...] Rockefeller philanthropies gave early support to demography and reproductive biology research and even to Kinsey's work in sexual behavior. But the Rockefeller Foundation's leaders began to have misgivings as to involvement in sensitive population matters, leading a frustrated John D. Rockefeller 3rd to establish the Population Council in 1952." (Harkavy, 1995, p. 2).
} 
Brasil foi, sem dúvida, seu apoio ao Cedeplar. De acordo com o depoimento de Mary Kritz, a Rockefeller fez uma primeira doação ao Cedeplar, em 1976, de US\$ 150 mil. Esse grant foi renovado, com valores diferentes, a cada três anos, até 1995. A Rockefeller, ao contrário da Ford, não tinha uma estrutura autônoma local e esse tipo de grant não se coadunava muito com as políticas da sede. Conseqüentemente, segundo Kritz, cada novo grant requeria uma longa negociação na sede da própria Rockefeller, para convencer os diretores da Fundação da importância do Brasil e do papel crítico de uma instituição como o Cedeplar.

De certa forma, a Rockefeller também copiou a estratégia da Ford ao enviar profissionais americanos para fortalecer 0 corpo técnico do Cedeplar. Porém, em vez de demógrafos já mais experientes, a Rockefeller enviou jovens recém-formados para que aprendessem algo a respeito dos países em desenvolvimento. Em si, esta estratégia - de usar o Cedeplar para capacitar jovens norte-americanos - demonstra que o ensino da instituição brasileira já estava sendo reconhecido como estando em outro patamar de qualidade no final da década de 70 . Desta forma vieram para o Brasil os jovens Steve Vosti e Frank Goza, entre outros. Os recursos da Rockefeller também permitiram a vinda de bolsistas africanos de língua portuguesa durante vários anos.

Adicionalmente, a Rockefeller forneceu US\$ 1 milhão para a área de biologia reprodutiva. Os principais beneficiários destes recursos foram o Centro de Pesquisas de Doenças da Unicamp (Cemicamp), cuja figura central era Aníbal Faundes, e a Universidade Federal da Bahia, no centro coordenado por Elzimar Coutinho.

Segundo Kritz, a Fundação Hewlett associou-se à iniciativa da Rockefeller em benefício do Cedeplar. Anne Murray era a oficial de programa da Hewlett, uma fundação nova e pequena, que foi influenciada pela Rockefeller no sentido de também apoiar o Cedeplar. A intenção destas contribuições era, claramente, desenvolver instituições fortes capazes de oferecer um ensino de boa qualidade e de realizar pesquisas no Brasil, em vez de mandar estudantes brasileiros para instituições acadêmicas nos países desenvolvidos. A Hewlett também deu um apoio importante aos estudos populacionais brasileiros de forma indireta, ao financiar um programa de população na Universidade de Austin, Texas. Este programa, coordenado pelo conhecido brazilianist Joe Potter, recebeu vários bolsistas e professores brasileiros e até instituiu um prêmio em honra a Vilmar Faria, destinado a profissionais brasileiros.

Conforme já mencionado anteriormente, o International Development Research Center (IDRC), organismo de assistência bilateral do governo canadense, já tinha apoiado, inter alia, a Pesquisa Nacional sobre Reprodução Humana realizada pelo Cebrap. Juntamente com a Ford, a Rockefeller e o Population Council, o IDRC apoiou a criação, em 1973, de um programa latino-americano - o Pispal - e, através deste, várias pesquisas no Brasil. O objetivo deste programa era gerar um interesse maior pelos temas populacionais na região, por intermédio de pesquisas realizadas por uma grande variedade de instituições. ${ }^{5}$ Esse programa durou até 1985 , momento em que os doadores começaram a canalizar seus recursos diretamente para as ONGs. No total, estima-se que o IDRC dispensou recursos no valor de aproximadamente US\$1,5 milhão ao Pispal.

Em suma, esses diversos doadores tiveram um papel importante no desenvolvimento dos estudos populacionais no Brasil. Seguindo a trilha marcada pela

\footnotetext{
5 "The objectives of the first two phases of this project included: stimulating interest in research on population and development interactions relevant to policy formulation, encouraging advances in conceptualization and methodology, assessing priorities, and encouraging research on them. The objectives of phase III are to study the relationship between population dynamics and socialeconomic change and to develop methodologies for conducting research in this area." Disponivel em: <http://web.idrc.ca/en/ev35280-201-1-DO TOPIC.html>
} 
Fundação Ford, eles apoiaram estudos e pesquisas em diversos âmbitos.

\section{Fundação MacArthur}

A trajetória da Fundação MacArthur no campo populacional no Brasil diverge de todas as contribuições anteriores de várias maneiras. As especificidades da trajetória da MacArthur têm seu início na nomeação de uma cientista social brasileira, Carmen Barroso, para o posto de diretora da recémcriada Divisão de População da Fundação, em 1989. Conhecida por seus trabalhos e sua militância, particularmente nas questões relacionadas com a saúde da mulher e gênero, Barroso imprimiu, através da MacArthur, uma nova orientação ao financiamento dos temas populacionais. Com o apoio da comunidade brasileira, o Programa da MacArthur foi, de certa forma, antevendo a visão mais ampla do Cairo sobre a questão populacional.

Em vez de trabalhar em todos os países, a MacArthur decidiu concentrar seus recursos em apenas quatro grandes países em desenvolvimento, entre os quais - Brasil. Em cada um destes países a Fundação começou seu trabalho com um amplo diagnóstico da questão populacional. Esse diagnóstico foi elaborado por um painel representativo de vários setores da sociedade, e não apenas com especialistas na área de população (Martine, 1991). Tratava também de temas muito mais abrangentes, enfatizando questões como a promoção da igualdade, o repúdio ao controle populacional e, vários anos antes do Cairo, já abordava questões de saúde sexual e reprodutiva.

Em suma, fundamentada na visão progressista e socialmente comprometida de Barroso, a MacArthur foi precursora de uma concepção mais abrangente dos temas populacionais; com isto a Fundação se distanciava claramente das outras entidades internacionais, e dilatava a compreensão do conceito de estudos populacionais. O modus operandi da Fundação também discrepava dos outros doadores no setor. Em vez de financiar pesquisas ou formação acadêmica, a MacArthur decidiu abrir um concurso para jovens profissionais com o intuito de selecionar, anualmente, oito profissionais ou ativistas que seriam agraciados, cada um, com uma bolsa de três anos. Os concursos eram abertos a uma grande variedade de profissionais e temas, incluindo jornalistas e artistas. Pretendiase que, com estes recursos, os bolsistas tivessem a tranqüilidade financeira para desenvolver pesquisas, trabalhos, estudos, publicações, ações etc. que requeriam um horizonte de tempo mais extenso. Por outro lado, a MacArthur propiciava encontros e apoio técnico aos bolsistas e, eventualmente, viagens de estudo e reconhecimento.

Esta modalidade de apoio, aplicada no Brasil por doze anos, permitiu a um número significativo de profissionais talentosos desenvolver suas capacidades e, ao mesmo tempo, realizar atividades de ação e/ou pesquisa em prol do desenvolvimento brasileiro. Indiretamente, essas atividades também serviram para ampliar a visão dos estudiosos de população no Brasil, dando maior destaque a questões de gênero, saúde reprodutiva, comunicação, meio ambiente e outros.

Com a mesma filosofia, a MacArthur também apoiou um grande número de entidades brasileiras destacadas tanto por seus compromissos ativistas como por sua excelência técnica, incluindo a Abep. É importante constatar que os primeiros GTs da Abep (Meio Ambiente e Gênero) também devem seus inícios a uma dotação da MacArthur. Um total de 73 entidades são listadas no relatório final do programa da Fundação no Brasil (MacArthur, 2003) como tendo recebido seu apoio. ${ }^{6}$ Embora o Brasil

\footnotetext{
${ }^{6}$ Os grupos beneficiados incluem, inter alia: Associação Brasileira Interdisciplinar de AIDS (Abia); Casa de Cultura da Mulher Negra Católicas pelo Direito de Decidir - Brasil; Centro Brasileiro de Análise e Planejamento (Cebrap); Centro Feminista de Estudos e Assessoria (CFEMEA); Cidadania, Estudo, Pesquisa, Informação e Ação (Cepia); Comunicação e Cultura - Instituto de Saúde e Desenvolvimento Social (ISDS); Instituto Sociedade, População e Natureza (ISPN); Cunhã - Coletivo Feminista; Ecos Comunicação em Sexualidade; Fala Preta - Organização de Mulheres Negras; Grupo de Trabalho e Pesquisa em Orientação Sexual (GTPOS); Ipas; Programa de Apoio ao Pai (Papai); Rede Nacional Feminista de Saúde e Direitos Reprodutivos; SOS-Corpo - Gênero e Cidadania; Themis - Assessoria Jurídica e Estudos de Gênero; Transas do Corpo.
} 
já não conste como um dos quatro países com tratamento preferencial, um endowment da MacArthur permite a continuação de apoios específicos.

\section{Usaid}

O papel da United States Agency for International Development (Usaid) no campo populacional é muito conhecido nas áreas de planejamento familiar e controle demográfico, nas quais passou a ser um dos principais atores mundiais a partir de 1965. ${ }^{7}$ Menos conhecido é o seu papel no campo da informação e da pesquisa demográfica. Na verdade, a Usaid foi um dos líderes mundiais na implementação de programas internacionais para o aprimoramento das fontes de dados básicos. ${ }^{8}$ No Brasil, deu uma assistência técnica considerável ao IBGE durante a década de 60. Sua influência foi particularmente marcante na origem das PNADs, que foram gestadas e desenvolvidas dentro da concepção de pesquisas contínuas domiciliares proposta para as Américas pelo US Bureau of the Census. ${ }^{9}$ Como resultado dessa iniciativa, as PNADs foram implantadas num momento estratégico. De fato, até aquela data, as fontes de informações básicas limitavam-se, essencialmente, aos censos decenais. Pior: o Censo Demográfico de 1960 havia afundado num marasmo de dificuldades operacionais e ninguém era capaz de prever se, ou quando, estas informações poderiam aparecer.

A idéia original dessa colaboração era

[...] criar um sistema relativamente fácil de manter, que investigasse algumas dezenas de milhares de domicílios de cada vez, permitindo, a nível agregado, [...] um acompanhamento sistemático do quadro socioeconômico do País. (US Bureau of the Census, 1969, s/p.)
Para tanto, o Plano Atlântida desenvolvia, detalhadamente, todos os aspectos de uma pesquisa contínua em base domiciliar: objetivos, conteúdo e desenho dos questionários, plano de amostragem, princípios de expansão da amostra, organização dos trabalhos de campo, manuais para entrevistadores etc. Os documentos do Plano Atlântida eram baseados na própria experiência do US Bureau of the Census, mas também incorporavam explicitamente as recomendações da ONU e dos acordos interamericanos.

Calcadas nas sugestões do Plano Atlântida, as PNADs foram implantadas no segundo trimestre de 1967, com periodicidade trimestral e cobertura geográfica parcial. No contexto sociopolítico daquele momento, o Brasil iniciava a era de ouro do planejamento tecnocrático. Começava também o período de grande generosidade dos empréstimos externos para financiar os programas e projetos colossais de infraestrutura e outros empreendimentos promovidos pelo governo militar (hoje conhecidos como "dívida externa"). A ausência de informações confiáveis em setores básicos era um empecilho importante a esse avanço da tecnocracia. As informações geradas pela PNAD eram uma promessa de que tais lacunas poderiam ser preenchidas.

Até meados da década de 70 , a PNAD constituía, praticamente, a única fonte confiável, abrangente e contínua de dados sobre emprego e renda. Outras fontes foram surgindo e a PNAD foi incorporando outros temas. Embora tenham sido interrompidas durante alguns anos, as PNADs foram ganhando em substância, periodicidade e cobertura geográfica até se transformarem, já na década de 80 , na principal fonte de informação socioeconômica corrente no

\footnotetext{
7 "USAID support for family planning and reproductive health (FP/RH) in Brazil continued for more than thirty years, from the late 1960 s until the program was officially closed in September 2000. USAID was the pioneer donor in providing family planning assistance in Brazil and, remarkably, remained the largest donor until 2000." (Merrick, Liljestrand e Pielemeier, 2000, p. 6).

${ }^{8}$ A discussão que segue é baseada em Martine et al. (1988).

9 "Durante a década de 60, a United States Agency for International Development (Usaid) e o Inter-American Statistical Institute (IASI) se empenharam em levar os países latino-americanos a implantar e desenvolver um sistema de inquéritos contínuos domiciliares, visando não somente proporcionar informações de interesse de cada país, mas também prover o continente de estatísticas populacionais que fossem comparáveis. O Brasil, com a ajuda da Usaid, consistiu em uma destas experiências de implantação, havendo-se adaptado às idéias contidas no documento de treinamento inicial, que serviu como ponto de partida para a elaboração da pesquisa, o Plano Atlântida." (US Bureau of the Census, 1969).
} 
país. A contribuição da Usaid a esse aspecto dos estudos populacionais é inegável. Entretanto, durante a década de 70, a Usaid restringiu seu apoio à área de controle populacional e, com isso, ficou relegada a um papel inexpressivo no cenário brasileiro.

Posteriormente, conforme é sabido até pelas gerações mais jovens, a Usaid foi o principal financiador das pesquisas de reprodução humana, as Demographic Health Surveys (DHS). Neste levantamento, feito por amostragem, coletam-se dados sobre fecundidade, nupcialidade, planejamento familiar, mortalidade infanto-juvenil e saúde materno-infantil, a partir de entrevistas domiciliares. A população alvo da pesquisa é composta por todas as mulheres de 15 a 44 anos de idade, independentemente do estado civil, e residentes nos domicílios visitados. No Brasil, essa pesquisa foi realizada em nível nacional em 1986 e 1991 e no âmbito apenas do Nordeste em 1996.

\section{FNUAP}

Conforme menção anterior, o Fundo de População das Nações Unidas (FNUAP) foi criado em 1969, tornando-se, em 1971, o organismo das Nações Unidas responsável por "programas de população". A história do FNUAP no Brasil pode ser dividida em dois períodos bem marcados, os quais correspondem a duas eras diferentes na trajetória do próprio Fundo.

No seu primeiro quarto de século de vida, o FNUAP era claramente parte do elenco de instituições internacionais criadas para propagar o planejamento familiar e, desta forma, estabilizar o crescimento populacional. Entretanto, esse objetivo central era mais diluído no Fundo que em outras instituições do gênero, pelo fato de que sua orientação e seu trabalho dependiam de um Conselho Executivo, no qual eram representadas as visões muito heterogêneas dos países integrantes da ONU sobre a questão populacional. De fato, pelo menos duas grandes regiões, África e América Latina, questionavam sistematicamente a solução do desenvolvimento via redução do ritmo de crescimento do denominador. Por causa destas discrepâncias, o FNUAP foi obrigado a adotar, na sua atuação em diferentes países, uma postura mais política e cautelosa, em relação ao controle populacional, que outras entidades doadoras. Para atender às demandas dos países em desenvolvimento e, ao mesmo tempo, escapar às acusações de controlista, o FNUAP apoiou, na maioria dos países, uma programação bastante ampla na qual o apoio ao planejamento familiar era balanceado com atividades de pesquisas, bolsas de estudos, geração ou melhoria de fontes de dados etc. Implicitamente, esperava-se que tais atividades levariam os diferentes países a formular políticas de população, entendidas essencialmente como políticas de redução da fecundidade. Nesse contexto, é interessante observar que no Brasil, país no qual a oposição ao controlismo era das mais intensas, essa abordagem mais equilibrada e diversificada custou muito a ser adotada pelo escritório local. De fato, até o período preparatório à Conferência Internacional de População e Desenvolvimento (CIPD) do Cairo, em 1994, a maior parte dos recursos do FNUAP aplicados no Brasil foi destinada às atividades e entidades de planejamento familiar. Tal discrepância pode ser explicada, pelo menos em parte, pela organização descentralizada do Fundo, cujos representantes locais acabavam tendo muita autonomia no manejo dos recursos institucionais, e pela postura da própria comunidade demográfica brasileira, que evitava demandar seus recursos, por entender ser o Fundo um agente do controlismo populacional.

Diversos fatores acabaram levando a uma mudança radical de postura do FNUAP a partir da Conferência do Cairo. Por um lado, continuavam as divergências entre os países a respeito da eficácia do controle populacional. Por outro, a ronda de censos de 1990 indicava claramente que a fecundidade estava caindo a ritmos inesperados e que o espectro da explosão demográfica estava definitivamente afastado, exceto em alguns países mais pobres. No entanto, o fator mais importante foi provavelmente a crescente oposição dos movimentos 
sociais, particularmente do movimento de mulheres, ao que se considerava uma atitude controlista do FNUAP e de outras entidades na área populacional. As diferentes "PrepComs" que antecederam a CIPD catalisaram essa oposição e obrigaram o Fundo a dar uma guinada de 180 graus na sua interpretação da questão populacional, sem a qual seu apoio político poderia ser irremediavelmente abalado.

Os avanços proporcionados pela Conferência do Cairo são sobejamente conhecidos e não valem a pena ser discutidos aqui. O importante, para a nossa finalidade, é observar a virada que este evento deu na atuação do FNUAP no Brasil. Já no período preparatório ao Cairo, o escritório local tratava de dar maior apoio aos estudos populacionais e à Abep. No período posterior à CIPD, e com uma liderança mais progressista na Divisão para América Latina e o Caribe, o Fundo passou a entender melhor a problemática brasileira e a apoiar uma série de atividades ligadas a gênero, população e desenvolvimento, e ensino, além de saúde reprodutiva.

Embora os recursos financeiros disponíveis para o programa do Fundo no Brasil estejam mais minguados, o impacto desse programa é hoje bastante mais significativo. De fato, tem havido uma relação cada vez mais sinérgica entre o FNUAP e a comunidade de estudos populacionais. Por um lado, o apoio do Fundo tem sido absolutamente crítico na realização das atividades da Comissão Nacional de População e Desenvolvimento (CNPD) e da própria Abep. Por outro, a CNPD e a Abep têm propiciado uma maior visibilidade e legitimidade ao FNUAP, participando ativamente da formulação do seu programa e na realização de atividades de promoção do Fundo.

\section{Referências bibliográficas}

BERQUÓ, E. A Fundação Ford e os estudos populacionais no Brasil: análisebalanço-testemunho. Trabalho elaborado

\section{Conclusão}

Malgrado as óbvias limitações das informações apresentadas neste ensaio, o papel central dos organismos e fundações internacionais nos estudos populacionais brasileiros fica bastante claro. Na formação profissional, na geração de dados, na realização de estudos e atividades de ensino, na formação de redes, a influência externa aparece como forte, quase imprescindível. Apesar disso, os intelectuais da demografia brasileira sempre se comportaram com muita independência e desprendimento, tanto no aspecto acadêmico como no ideológico. De fato, nasceram daqui muitas das contestações ao controlismo que acabaram encontrando ressonância e uma maior difusão na CIPD.

O grande desafio, nessa época em que os recursos internacionais para atividades na área de população estão minguando, é garantir a sustentabilidade dos estudos de população no contexto brasileiro. $O$ fato concreto é que nos encontramos num momento de inflexão no que se refere ao financiamento dos estudos de população. É preocupante a falta de auto-suficiência, tendo em vista a retirada dos recursos privilegiados que a área de população recebia para capacitação e pesquisa. Isto tudo nos obriga a pensar em novas estratégias de renovação para manter vivo o interesse nos temas populacionais e para garantir que eles conservem e mesmo aumentem sua relevância nas agendas nacionais. De outra forma, é inevitável que o esforço feito na área de população durante os últimos 40 anos definhe. Portanto, temos aí um grande desafio: como sobreviver e crescer em tempos de recursos externos declinantes? Certamente, a criatividade da nossa juventude, apoiada pela sabedoria dos mais "experientes", será capaz de gerar soluções adequadas.

para o seminário "30 anos de Fundação Ford no Brasil: retrospecto, impactos e perspectivas", Rio de Janeiro, 1992. 
BERQUÓ, E. e BERCOVICH, A. Redescobrindo o Brasil: viagem à demografia de Giorgio Mortara. Revista Brasileira de Estudos de População, v. 2, n. 2, p. 21-36, 1985.

DEMENY, P. Population and development. Distinguished Lecture Series on Population and Development, IUSSP/ICPD, Cairo, 1994.

EHRLICH, P.R., EHRLICH, A.H. e DAILY, G.C. The stork and the plow: the equity answer to the human dilemma. Nova York: G.P. Putnam's Sons, 1995.

HARKAVY, O. Curbing population growth: an insider's perspective on the population movement. Nova York/Londres: Plenum Press, 1995.

HODGSON, D. The ideological origins of the Population Association of America. Population and Development Review, 17(1), p. 1-34, 1991.

LOPES, V. A contribuição de organismos internacionais para a demografia brasileira (notas para um artigo). Comunicação pessoal, 11 nov. 2004.

MACARTHUR FOUNDATION. 1990-2002. The population and reproductive health program in Brazil: lessons learned. Chicago: The John D. and Catherine T. MacArthur Foundation, 2003.

MARTINE, G. (Ed.). Migrações internas. Rio de Janeiro: Altiva Gráfica e Editora, 1977.

MARTINE, G. A questão populacional no Brasil: elementos para a agenda da
Fundação MacArthur. Documento de trabalho da Fundação MacArthur, 1991.

MARTINE, G., CAMARANO, A.A., FLETCHER, P. e NEUPERT, R. A PNAD: notas para uma avaliação. In: SAWYER, D. (Org.), PNADs em foco: anos 80. Belo Horizonte: Abep, 1988, p. 281-305.

MARTINE, G. e FARIA, V.E. Contexto social da política e da pesquisa populacional no Brasil. Revista Brasileira de Estudos de População, v. 3, n. 1, p. 1-24, 1986.

MERRICK, T., LILJESTRAND. J. e PIELEMEIER, $J$. USAID support for family planning/ reproductive health in Brazil. USAID, POPTECH Assignment Number: 2000.175, June 2000.

MUNDIGO, A. Brazil notes. Comunicação pessoal, 21 out. 2004.

SZRETER, Simon. The idea of demographic transition and the study of fertility change: a critical intellectual history. Population and Development Review, 19(4), p. 659701, 1993.

UNITED NATIONS. Population Division. Determinants and consequences of population trends. Nova York: UN Economic and Social Affairs, 1953.

US BUREAU OF THE CENSUS. Atlântida: un estudio de caso en encuestas de hogares por muestra. Series ISPOL, Washington, DC, 1969.

WILMOTH, J.R. e BALL, P. The population debate in American popular magazines. Population and Development Review, 18(4), p. 631-668, 1992. 


\section{Anexo}

QUADRO 1

Projetos do Nepo com recursos internacionais

\begin{tabular}{lll}
\hline Projetos & Financiadores & Início-Término \\
\hline $\begin{array}{l}\text { Educação indígena no Alto Rio Negro } \\
\begin{array}{l}\text { Estudo multicêntrico sobre o impacto da } \\
\text { nova legislação brasileira a respeito da } \\
\text { esterilização voluntária }\end{array}\end{array}$ & Fundação MacArthur & $1999-2001$ \\
$\begin{array}{l}\text { Experiência piloto de aplicação dos indicadores } \\
\text { municipais de saúde sexual e reprodutiva }\end{array}$ & FNUAP & $1999-2001$ \\
$\begin{array}{l}\text { Programa de saúde reprodutiva e sexualidade } \\
\begin{array}{l}\text { Programa interinstitucional de treinamento } \\
\text { em metodologia de pesquisa em gênero, } \\
\text { sexualidade e saúde reprodutiva }\end{array}\end{array}$ & Fundação Ford & 2002-2006 \\
$\begin{array}{l}\text { Programa interinstitucional de avaliação e } \\
\text { acompanhamento das migrações } \\
\text { internacionais no Brasil }\end{array}$ & Fundação Ford & 1990-2004 \\
$\begin{array}{l}\text { Projeto Brasil Latino, Cátedra A 02: Migração, } \\
\text { humanismo latino e territorialidade na } \\
\text { sociedade paulista (1850-1950) }\end{array}$ & FNUAP & $1994-2004$ \\
\hline
\end{tabular}

QUADRO 2

Apoios internacionais recebidos pelo CRH-UFBA para pesquisas e bolsas

Population Council: 1970; 1971

Fundação Rockefeller: 1973-75; 1975; 1978; $1987-90$

Fundação Ford: 1971; 1982; 1982; 1982; 1988; 1988; 1989-90; 1989-92; 1996-97

Banco Mundial: 1978-80

Credal/Université de Paris III: 1981-85; 1985-87; 1988-89; 1992-96

Orstom: 1986-91; 1987-92

Inserm: 1994-97; 1994-96

Pispal/Clacso: 1982

Clacso: 1998-99

OEA: 1987

Unam: 1988

Fundação MacArthur: 1993-96

Interamerican Foundation: 1988; 1989; 1990; 1990-91

Unicef: 2000

FNUAP: 2004

Fonte: Lista preparada pelo CRH-UFBA, por intermédio de Guaraci Adeodato Alves de Souza 


\begin{abstract}
The role of international organisms in the evolution of population studies in Brazil: preliminary notes

This article analyzes the influence of international donor agencies on the evolution of population studies in Brazil. The exceptional growth of demography in this country was generated, in part, by international concern with population growth and by the resources made available to us. International agencies that wished to influence population issues in Brazil had two choices. Until the Cairo Conference, USAID and UNFPA operated primarily through alliances with organizations that promoted family planning, related to fertility reduction. The Ford Foundation, the Pan-American Health Organization, the Population Council, and the Rockefeller Foundation chose a less direct strategy, which was more useful for Brazil. They encouraged the formation of a critical mass capable of taking the initiative for political thought in the domain of population. Directly or indirectly, this approach ended up benefiting researchers as well as the various learning and research institutions now existing in Brazil. The international donor with the greatest long-term influence in Brazil was the Ford Foundation. The MacArthur Foundation adopted a new approach to the financing of population studies, anticipating the vision drawn up in Cairo. Today, the post Cairo version of UNFPA is practically the only donor that continues to support us systematically, a situation that forces us to find new approaches in order to continue expanding the influence of population studies in the future.
\end{abstract}

Key words: International research funding agencies. Progress in demographic studies. Demographic policies. Brazil.

Recebido para publicação em 25/01/2005. Aceito para publicação em 24/06/2005. 